\title{
Development and Application of the Problem- Oriented Language FORTU for the Design of Non-Standard Mechanical Constructions
}

\author{
V. Mezhuyev', V. Lavrik$^{2}$, S. Ravi $^{3}$ \\ ${ }^{1}$ Faculty of Computer Systems and Software Engineering, University Malaysia Pahang, \\ Malaysia \\ ${ }^{2}$ Department of Informatics and Software Engineering Berdyansk State Pedagogical University, \\ Ukraine \\ ${ }^{3}$ Faculty of EEE, Selvam College of Technology, India
}

\begin{abstract}
This paper introduces a new problem-oriented language FORTU, which allows engineers to easily develop various methods for the design and analysis of non-standard mechanical constructions. It is implemented in the FORTU-FEM Computer-Aided Design (CAD) system which mathematical base is the Finite-Element Method (FEM). Due to using FORTU language, FORTU-FEM has an open architecture and allows its users to change the schema of computation. An example of FORTU-FEM application for computation of the tensional and the deformed states of mechanical constructions is considered.
\end{abstract}

Keywords: Computer-Aided Design; Problem-Oriented Language; Finite-Element Method; FORTU-FEM, Open Architecture.

\section{Introduction}

The traditional approach for the development of software that automates computer-aided design can be described by the following scheme:

a) a user formulates a list of requirements for a future software system;

b) a specialist in the given domain gives specifications for a software product;

c) a system analyst develops an algorithm for solving a problem;

d) a programmer implements a software product, that meets the initial requirements of a user.

In this scheme, the following shortcomings can be seen:

a) separation of a specialist in a specific domain from the process of software development, while its quality directly affects efficiency of solution of the original problem;

b) involvement of a number of specialists in the process of software system development, which significantly increases the design time and the cost of a final product;

c) necessity to repeat all the above mentioned phases of the software development if a user needs to add a new feature of functionality or to change an algorithm for solving the problem.

A CAD system, developed by the above described traditional scheme, will also have limitations: 
- it is impossible without redevelopment of the program to change formulation and the method for solving an original problem, because final software implements a concrete algorithm;

- a target software can only be used as a standalone one, because the development of interfaces with other existing CAD systems is a complicated task.

Let us also note here that modern CAD tools for exploring properties of mechanical systems, support a number of mathematical methods for approximate computations (to solve the big systems of algebraic and transcendental equations, numerical integration and differentiation etc.), but do not often give a possibility of realization of non-standard computations.

To overcome these problems it is necessary to design a CAD system, which has an open architecture, i.e. that would allow their users - specialists in a specific domain - to develop their own models and methods, define schemas of computation, and thus, describe an arbitrary automation process. For this purpose, specification of a domain (object decomposition, allocation of their attributes, definition of methods for the modelling and analysis) should be done in the terms which are close to the user's domain of expertise.

This task lies inside the general problem of development of Domain Specific Languages (DSL) for systems engineering (Mezhuyev 2014). In our previous works we proposed the methodology of domain specific mathematical modelling (Mezhuyev 2014a), allowing development of DSLs for modelling domains that have a different mathematical structure (Mezhuyev 2015).

In this paper we propose a DSL FORTU, based on energetic variational principle (which mathematical base was considered in Mezhuyev, Lavrik 2014). DSL FORTU is used in FORTU-FEM CAD system, intended for the design of non-standard mechanical constructions, being in the tensional and the deformed conditions. Applications of FORTU-FEM CAD system was considered in our previous works (Lavrik et al. 2014; Mezhuyev, Lavrik 2014a). This paper analyses the principles of development and use of the problem-oriented language FORTU for computer based design in more details.

Using FORTU language, by the given minimum of input information and the large-scale scheme of computation, which corresponds to the minimization of energetic functional, a user interactively realizes the process of analysis and numerical solution of non-standard problems of firm bodies, being in the stress and deformed states. Flexibility of FORTU-FEM allows its users to change both formulation of the problem and the computation scheme.

This paper is organized as follows. First, we analyse existing problem-oriented approaches and present the general structure and open architecture of the CAD system FORTU- FEM. We discuss the method for a formal description of mechanical problems and their solution with a specially developed problem-oriented language FORTU. The concept sample of using FORTU for the design of non-standard mechanical constructions is given. Conclusions and prospects for the future research finalize this paper.

\section{Analyses of existing approaches}

Most of the modern CAD systems, such as ANSYS (2003), COSMOS (1989), NASTRAN have closed modular architecture. For example, Fig. 1 shows the structure of the COSMOS CAD system. In terms of its functionality, COSMOS is a closed software system. Algorithms, used in the modules of the COSMOS, are based on the Finite-Element Method (FEM). 
By using software components shown in Fig. 1, a COSMOS user may implement the entire design process: create a geometrical model; perform its sampling on Finite Elements (FE); specify the type and parameters of computation; perform the analysis and get the final results.

Due to a unified approach for problems solving, this CAD system allows its users to perform analysis of large classes of tasks of mathematical physics: statics, dynamics in a linear and non-linear formulations; fatigue strength; modelling stationary and non-stationary thermal processes; solving problems of the low-frequency and high-frequency electromagnetics; gas dynamics, and also a number of other tasks.

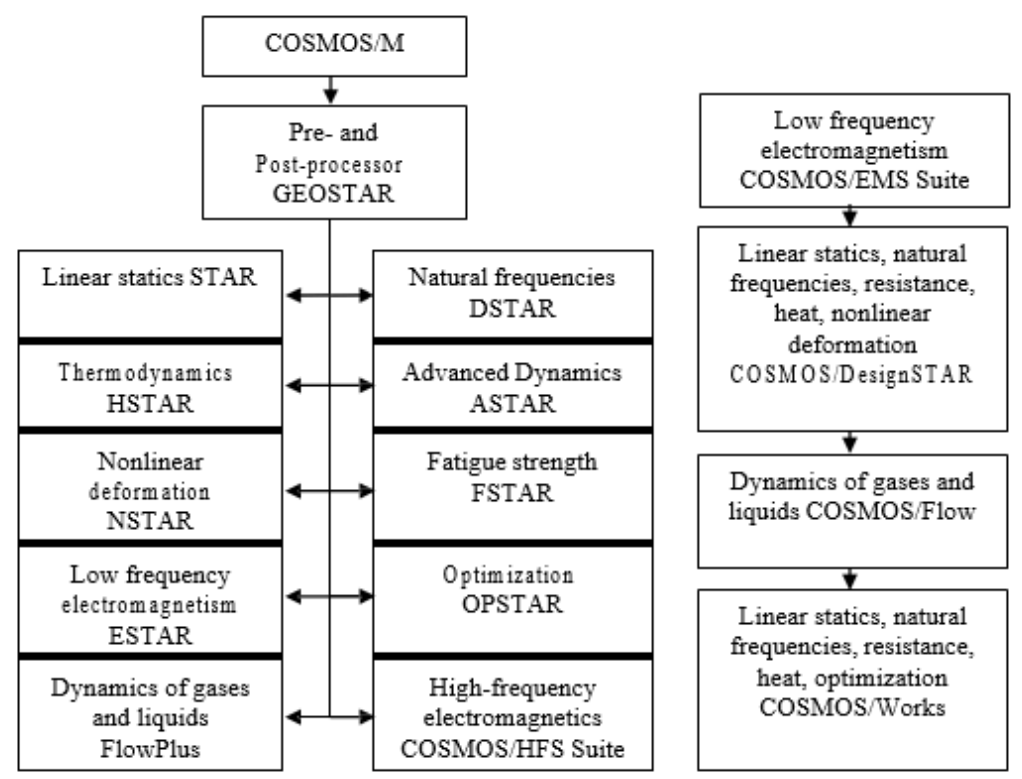

Fig. 1. The system architecture of COSMOSCAD

Note that such modular architecture is characteristic for most of other "heavy" CADs, such as COSAR, PATRAN, LIRA (Liraland). Taking into account their power, it should be noted that modification of such CAD systems, e.g. enhancement of their functional characteristics, requires time-consuming redevelopment of different interlinked software modules composing this tool.

Let us consider a solution for this problem by design of the open architecture CAD system, which uses a specially developed DSL to describe the broad classes of problems of mathematical physics and the methods for their solution.

\section{Design of the open architecture FORTU-FEM CAD System}

The CAD system FORTU-FEM (Lavrik et al. 2014; Mezhuyev, Lavrik 2014 a) was initially developed in Zaporizhia National University, Ukraine. Judging from its name, FORTU-FEM uses the finite elements method for solving different problems in solid mechanics.

The FORTU-FEM CAD system was developed to automate the design of complex engineering constructions and buildings, and supports analysis of their stress and strain states. 
Unlike most existing CADs, FORTU-FEM allows its user to describe the process of a problem solution in terms which are close to a considered domain.

The design of FORTU-FEM allows us to combine several directions in the development of the problem-oriented CADs. The specialized source language FORTU gives a possibility to the user-nonprogrammer to formalize a description of a specific problem of mathematical physics in terms of domain and to make calculations correspondingly to the developed computation scheme.

As the mathematical base for the solution of non-standard problems of mechanics the variations calculus is taken, allowing users to describe in the most general formal form the energy of the system and the method for its minimization. This approach allows users to easily develop solutions for the different types of complex mechanical problems. It is important to note that for the development of the computation scheme, it is only necessary to describe the rules for inferring the main relations of the variational functional and to choose the method to find its minimum.

Fig. 2 shows the general scheme of FORTU-FEM CAD system. It consists of three main modules: the subsystem for the preparation of initial data (pre- processor), the subsystem for the numerical calculation (processor) and the subsystem for analysis of achieved numerical results (post-processor).

The FORTU-FEM pre-processor includes a module for geometrical modelling, allowing engineers to create a two- or a three-dimensional space model of designing object. There is also a module for discretization of a geometrical region on the finite or the boundary elements. It allows us to design a geometrical model of a mechanical object, sample it by a user-defined types of the finite or the boundary elements, and to develop a mathematical model in FORTU language. Pre-processor also includes the database of model constructions.

Processor - a core of FORTU-FEM CAD system, which includes problem-oriented software modules to perform all needed types of computations. The composition of these modules allows users to develop a computational scheme for analysis of stress and strain characteristics of a designed mechanical object.

The processor includes an interpreter of FORTU language, which performs verification of a source program, and finally makes all necessary computations, described in the form of FORTU model. The processor automates the development of a system of linear algebraic equations, which a user needs to solve to have numerical results. Through the use of efficient algorithms, the processor of FORTU system can effectively solve the linear algebraic equations of the extra-large orders.

The post-processor supports analysis of results of computation (incl. accuracy of calculations) and also generates all the necessary project documentation for a designed mechanical object. The heart of the postprocessor is a block for visual analysis, which allows us to represent the results of computations in 2D and 3D formats using different lightings (see Fig. $3)$. The postprocessor also includes the database of designed constructions.

FORTU-FEM CAD system supports their users in the next processes:

a) formally describes a topology of geometrical domain of any complexity;

b) splits a source geometrical region into a given number of subdomains;

c) makes discretization of an arbitrary geometrical region;

d) formulates boundary conditions for the problem;

e) forms and solves a matrix system of equations;

f) updates characteristics of the mechanical system in accordance with results of a solution. 
The general scheme of mechanical design using FORTU-FEM is as follows. A user starts with the development of a geometrical model and continues with FORTU for the development of a computational scheme. FORTU-FEM systems support users in forming a system of Linear Integro-Differential Equations (LIDR), their solving, visualisation of results and generation of all necessary documentation.

The success of the design of a mechanical system directly depends on the correctness of the model, defined in the problem-oriented language FORTU. The accuracy of the solution depends on the user-selected types of finite elements, the density and the structure of the FE mesh, and also a computation scheme.

Definition of a computation scheme is an application of variational principle, being a powerful and a formal way of describing mathematical model of a mechanical object or a process. The FORTU language was developed to support users in application of this principle for the design of mechanical systems. This language is further considered in more details.

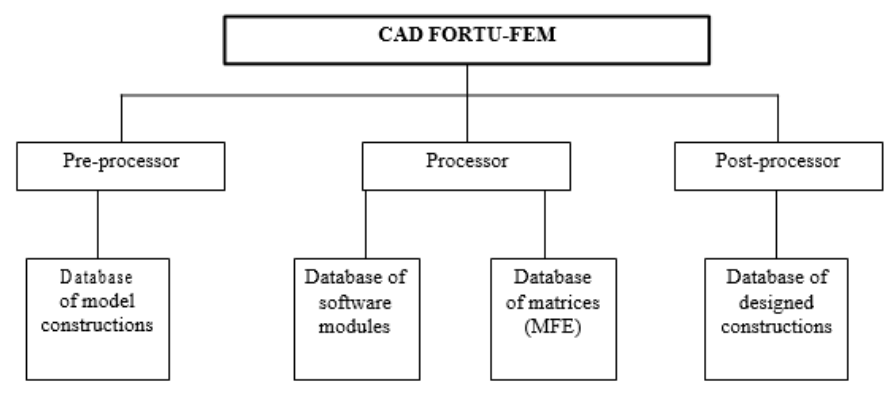

Fig. 2. Structure of computer-aided design system FORTU-FEM

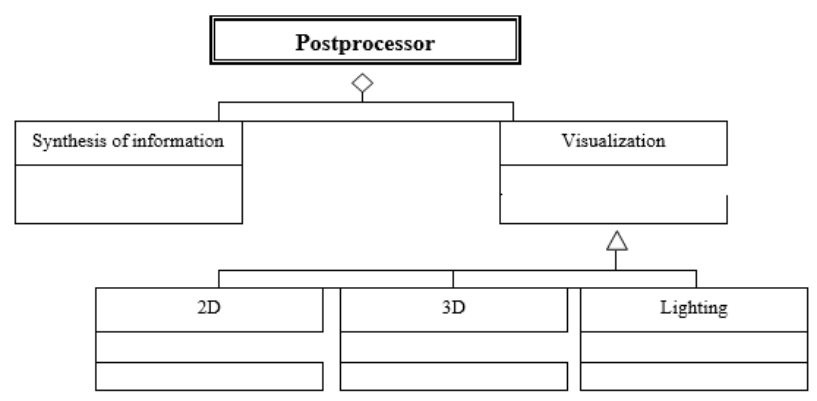

Fig. 3. The model of a post-processor of FORTU-FEM

\section{Study of an elongation of a prismatic rod under its own weight}

To show possibilities of FORTU language we should consider a simple problem from elasticity theory. A prismatic rod is rigidly fixed on the one side and is extended under its own weight to the other side (Fig. 4). 


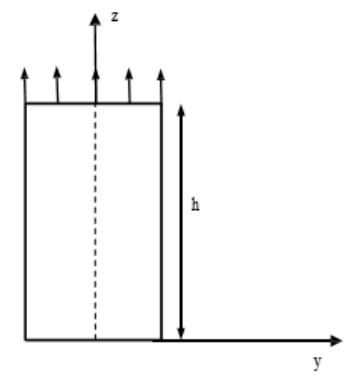

Fig. 4. The schema of a strain of a prismatic rod under its own weight

The input parameters are the following: the size of the rod is $0,01 \times 0,01 \mathrm{~m}$, its height $h=$ $0,02 \mathrm{~m}$, the elastic modulus is $E=2 \mathrm{MPa}$, the density of the material is $\rho=1200 \mathrm{~kg} / \mathrm{m}^{3}$, the Poisson ratio is $v=0,49$.

The analytical solution for this problem we may obtain from the formula:

$$
w=-\frac{\rho g}{2 E}\left(h^{2}-z^{2}\right)
$$

which expresses the shift of points on the axis $\mathrm{Z}$. By this formula, the maximum elongation for such construction is $w=11,76 \cdot 10^{-7} \mathrm{~m}$.

FORTU program is used to solve this problem:

OBJECT plita3d plita3d.BEGIN

RESULT $u, v, w$ ARGUMENT $x, y, z$ CONSTANT $E, G, m, L$

FUNCTION Exx, Eyy, Ezz, Gxy, Gxz, Gyz, Sxx,

Syy, Szz, Txy, Txz, Tyz

RIGHT $X, Y, Z$ FUNCTIONAL $U$ TRANSFORM $u, v, w$

OUTPUT Exx, Eyy, Ezz, Gxy, Gxz, Gyz, Sxx, Syy, Szz, Txy, Txz, Tyz

$E=2 * 10^{\wedge} 6 m=0.49$

$G=E /(2.0+2.0 * m)$

$L=2 * m * G /(1-2 * m)$

$E x x=\operatorname{diff}(u, x)$

Eyy $=\operatorname{diff}(v, y)$

$E z z=\operatorname{diff}(w, z)$

$G x y=\operatorname{diff}(u, y)+\operatorname{diff}(v, x)$

$G x z=\operatorname{diff}(u, z)+\operatorname{diff}(w, x)$

$G y z=\operatorname{diff}(w, y)+\operatorname{diff}(v, z)$

$S x x=2 * G * E x x+L *(E x x+E y y+E z z)$

$S y y=2 * G * E y y+L *(E x x+E y y+E z z)$

$S z z=2 * G * E z z+L *(E x x+E y y+E z z)$

$T x y=G * G x y$ 
$T x z=G * G x z$

$T y z=G * G y z$

$X=0$

$Y=0$

$Z=29500$

$U=0.5 *$ Integral $($ Sxx \& Exx + Syy \& Eyy + Szz \& Ezz + Txy \& Gxy + Txz \& Gxz+Tyz\& Gyz) $-0.5 * I n t e g r a l(X \& u+$ $Y \& v+Z \& w)$

$u(z=0)=0 v(z=0)=0 w(z=0)=0$

Table 1. shows the results of computations by the method of moment diagrams (Boffi et al. 2013 ) in the case of an irregular partitioning into finite elements.

\begin{tabular}{|r|r|r|c|}
\hline № & Number of FE & Number of nodes & $\begin{array}{c}\mathrm{w} \\
\times 10^{-7} \mathbf{M}\end{array}$ \\
\hline 1 & 69 & 39 & 10,81 \\
\hline 2 & 176 & 66 & 10,55 \\
\hline 3 & 337 & 138 & 11,03 \\
\hline 4 & 558 & 198 & 11,12 \\
\hline $\mathbf{5}$ & $\mathbf{1 2 5 8}$ & $\mathbf{3 7 1}$ & $\mathbf{1 2 , 0 0}$ \\
\hline 6 & 4345 & 1239 & 12,51 \\
\hline 7 & 9828 & 2247 & 12,93 \\
\hline 8 & 11109 & 2618 & 12,97 \\
\hline
\end{tabular}

Table 1. The results of the computations of a prismatic rod

The best result $w=12,00 \cdot 10^{-7} \mathrm{~m}$ is achieved, when the tension of a prismatic rod is obtained by splitting it into 1258 FE. Fig. 5 shows a graph, comparing results of shifting nodes at optimal partitioning into FE located on the $\mathrm{Z}$ axis, calculated by the FORTU-FEM system and by using the analytical formula.

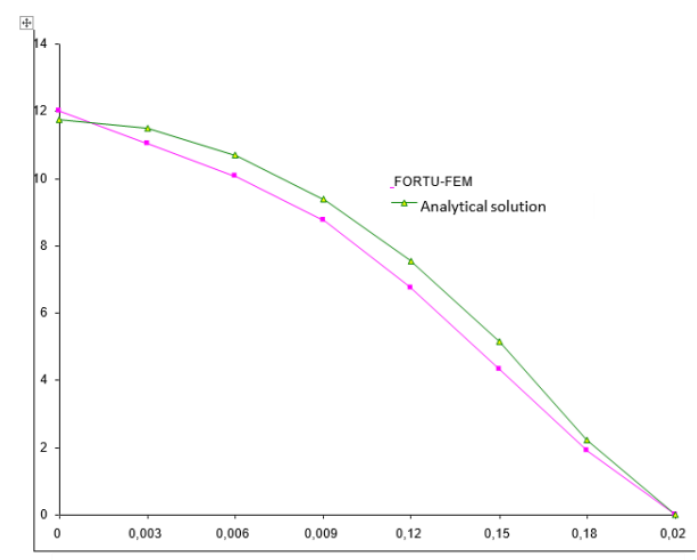

Fig. 5. Comparison of the results of calculation of the prismatic rod with the help of FORTUFEM and analytical solution 
This example shows good correspondence of the results obtained in FORTU-FEM with the analytical solution.

\title{
5. Conclusion and prospects for the future research
}

Given analyses show limitations of existing approaches for the development of modern CAD software. To overcome these drawbacks we propose a new solution - a CAD system, which has an open architecture. It allows users to develop models and methods, define schemas of computation, describe an arbitrary automation process in the terms, which are close to the user's domain of expertise. This is possible due to the definition and use of the special problemoriented language FORTU, built in the terms of energetic variational principle.

Operating FORTU language, by the given minimum of input information and the largescale scheme of computation, corresponding to the minimization of energetic functional, a user interactively realizes the process of analysis and numerical solution of non- standard problems of mechanics. Flexibility of FORTU- FEM allows its users to change both formulation of the problem and the computation scheme.

The main direction of our work is a further improvement of FORTU language by expanding its grammar and adding constructions will will allow users to effectively develop new methods for analysis and computation of non-standard mechanical problems.

Извод

\section{Развој и примена програмски оријентисаног језика FORTU на дизајн нестандардних механичких конструкција}

\author{
V. Mezhuyev ${ }^{1}$, V. Lavrik ${ }^{2}$, S.Ravi $^{3}$ \\ ${ }^{1}$ Faculty of Computer Systems and Software Engineering, University Malaysia Pahang, \\ Malaysia \\ ${ }^{2}$ Department of Informatics and Software Engineering Berdyansk State PedagogicalUniversity, \\ Ukraine \\ ${ }^{3}$ Faculty of EEE, Selvam College of Technology, India
}

\section{Резиме}

Рад уводи нови проблемски оријентисани језик FORTU, који омогућава инжењерима да лако развију различите методе за дизајн и анализу нестандардних механичких конструкција. Примењен је у FORTU-FEM CAD систему, чија је математичка основа метода коначних елемената (FEM). Због коришћења FORTU језика, FORTU-FEM има отворени програмски код и омогућава корисницима да измене начин прорачуна. Разматра ce пример FORTU-FEM примене на прорачун напонских и деформисаних стања механичких конструкција.

Кључне речи: CAD, проблемски оријентисани језик, метода коначних елемената, FORTU-FEM, отворени програмски код. 


\section{References}

Autodesk Nastran In-CAD. http://www.autodesk.com/products/nastran-in-cad/overview

Boffi D, Brezzi F, Fortin M (2013). Mixed Finite Element Methods and Applications. Springer Series in Computational Mathematics, 44, 685 p.

Dubinsky C. ANSYS 8.0: What's New. CAD and graphics. №11. 2003.

Group LiraLand http://www.liraland.ru/

Lavrik V, Cortez JI, Mezhuyev V, Cortez L, Alekseeva A, García GT, Juarez PG, Poblano J (2014). Development of the CAD system for designing non-standard constructions from elastomers. International Journal of Innovative Research in Science, Engineering and Technology 3, 3, 10717-10726.

Mezhuyev V, Lavrik V (2014). Output circuit of difference relationships on the base of Lagrange variation principle. Matem. Mod., 26, 12, 127-136.

Mezhuyev V, Lavrik V (2014a). Development and application of FORTU-FEM ComputerAided Design System. Proceedings of 4th World Congress on Information and Communication Technologies WICT 2014 (Malacca, Malaysia, 8-11 December 2014), 249-352.

Mezhuyev V (2014). Ontology Based Development of Domain Specific Languages for Systems Engineering. International Conference on Computer and Information Sciences ICCOINS2014 (Kuala-Lumpur, Malaysia, 3-5 June 2014), 1-6.

Mezhuyev V (2014a). Methodology of Domain Specific Mathematical Modelling. Proceedings of the 3rd International Congress on Natural Sciences and Engineering ICNSE 2014 (Kyoto, Japan, May 7-9, 2014), 54-64.

Mezhuyev V (2015). Metamodelling Architecture for Modelling Domains with Different Mathematical Structure. Advanced Computer and Communication Engineering Technology. Lecture Notes in Electrical Engineering, 315, 1049-1055.

User reference manual for COSMOS / M BASIC SYS. (1989). Los Angeles: Structural Research \& Analysis Corp., 694 p. 